\title{
Article \\ Molecular Characterization of U-box E3 Ubiquitin Ligases (TaPUB2 and TaPUB3) Involved in the Positive Regulation of Drought Stress Response in Arabidopsis
}

\author{
Jae Ho Kim ${ }^{\dagger}$, Moon Seok Kim ${ }^{\dagger}$, Dae Yeon Kim, Joseph Noble Amoah and Yong Weon Seo ${ }^{*}$ \\ Department of Plant Biotechnology, Korea University, Seoul 02841, Korea; jhkim169@korea.ac.kr (J.H.K.); \\ kms7421322@korea.ac.kr (M.S.K.); dykim@korea.ac.kr (D.Y.K.); jamoah@korea.ac.kr (J.N.A.) \\ * Correspondence: seoag@korea.ac.kr \\ † These authors contributed equally to this work.
}

Citation: Kim, J.H.; Kim, M.S.; Kim, D.Y.; Amoah, J.N.; Seo, Y.W.

Molecular Characterization of U-box E3 Ubiquitin Ligases (TaPUB2 and TaPUB3) Involved in the Positive Regulation of Drought Stress Response in Arabidopsis. Int. J. Mol. Sci. 2021, 22, 13658. https://doi.org/ $10.3390 /$ ijms222413658

Academic Editor: Esther M. González

Received: 17 November 2021 Accepted: 18 December 2021 Published: 20 December 2021

Publisher's Note: MDPI stays neutral with regard to jurisdictional claims in published maps and institutional affiliations.

Copyright: () 2021 by the authors. Licensee MDPI, Basel, Switzerland. This article is an open access article distributed under the terms and conditions of the Creative Commons Attribution (CC BY) license (https:// creativecommons.org/licenses/by/ $4.0 /)$.

\begin{abstract}
Plant U-box E3 ubiquitin ligase (PUB) is involved in various environmental stress conditions. However, the molecular mechanism of U-box proteins in response to abiotic stress in wheat remains unknown. In this study, two U-box E3 ligase genes (TaPUB2 and TaPUB3), which are highly expressed in response to adverse abiotic stresses, were isolated from common wheat, and their cellular functions were characterized under drought stress. Transient expression assay revealed that TaPUB2 was localized in the cytoplasm and Golgi apparatus, whereas TaPUB3 was expressed only in the Golgi apparatus in wheat protoplasts. Additionally, TaPUB2 and TaPUB3 underwent self-ubiquitination. Moreover, TaPUB2/TaPUB3 heterodimer was identified in yeast and the cytoplasm of wheat protoplasts using a pull-down assay and bimolecular fluorescence complementation analysis. Heterogeneous overexpression of TaPUB2 and TaPUB3 conferred tolerance to drought stress. Taken together, these results implied that the heterodimeric form of U-box E3 ubiquitin ligases (TaPUB2/TaPUB3) responded to abiotic stress and roles as a positive regulator of drought stress tolerance.
\end{abstract}

Keywords: wheat; plant U-box E3 ligase; drought; ubiquitination; TaPUB2; TaPUB3

\section{Introduction}

Plants are consistently exposed to adverse environmental conditions throughout their life cycle. They are regularly subjected to harmful environmental cues that affect their growth, development, and yield. Therefore, plants have evolved various physiological, biochemical, and molecular strategies to cope with these extreme environmental conditions [1,2]. Although the metabolic response to drought stress in various crops has been widely studied, little is known about the molecular mechanisms underlying drought tolerance, especially in wheat. Therefore, the study of stress responsive genes in wheat would clarify its response to various conditions.

Wheat (Triticum aestivum L.) is an economically important cereal crop in the developing world, as an estimated 80 million farmers depend on wheat for their livelihood [3]. Recurrent droughts caused by climate change are a major constraint on the global wheat productivity [4]. Recently, numerous efforts have been made to mitigate drought stress by breeding drought-resistant varieties. However, wheat has a large and structurally complex genome, and drought tolerance in wheat is a complex trait that is controlled by many genes. To date, several candidate genes for drought stress tolerance in wheat have been reported. TaMYB31-B overexpression in Arabidopsis has been shown to regulate the drought stress response in an abscisic acid (ABA)-dependent manner [5]. TaAREB3 (ABA response element binding 3), a new member of the AREB transcription factor family, not only enhances drought tolerance, but also strengthens ABA sensitivity and cold tolerance [6]. Moreover, wheat E3 ligase (TaSAP5) is highly induced by drought stress and ubiquitinates defective 
ribosomal products, which are negative regulators of DREAB2A, by promoting their degradation via the $26 \mathrm{~S}$ proteasome pathway [7]. Furthermore, the overexpression of TaFBA1 was reported to be a positive response to drought stress, and it increases reactive oxygen species (ROS) scavenging, which improves plant tolerance to drought conditions [8].

Post-translational modifications play a crucial role in plant metabolism by modulating transport, cell fate and development, structural support, and transcription [9]. The ubiquitin (Ub)-proteasome system (UPS) plays a vital role in the regulatory mechanism of protein ubiquitination and degradation in plants. The UPS degrades a wide range of proteins in plant organelles, thereby regulating growth, hormone signaling, and abiotic stress responses [10]. In this process, mono- or poly-ubiquitin attaches to the substrate by E1 (ubiquitin-activating enzyme), E2 (conjugating enzyme), and ubiquitin E3 ligase. Among these, E3 ligase regulates an essential rule of the induced target substrate gene or protein level.

In plants, E3 ligases can be divided into four main classes depending on the presence of HECT (HOMOLOGY TO E6-AP C-TERMINUS), RING (REALLY INTERESTING NEW GENE)/PUB (Plant U-box), SCF (SKP1-CULLIN-F-box), and APC (Anaphase-Promoting Complex) [11]. The U-box protein was first isolated in yeast; it possesses E3 ligase activity and comprises approximately 70 amino acids $[12,13]$. PUB genes have previously been identified, and mutations (such as deletions) in the U-box domain have been found to reduce E3 ligase activity $[14,15]$. PUBs have been discovered in the genomes of many plant species. For example, a recent genome-wide analysis revealed 66, 77, and 213 PUBs in Arabidopsis thaliana (AtPUB) [16], rice (OsPUB) [17], and wheat (TaPUB) genome, respectively [18]. U-box-ARM (armadillo)-encoded proteins have been implicated in the regulation of various biotic and abiotic pathways, such as cell death, defense response, cold stress, and salt stress pathways [19-21]. U-box proteins also affect other pathways; they play important roles in self-incompatibility [22], pseudo-self-incompatibility [23], hormone regulation [24], and plant development [25]. U-box-containing genes have previously been identified in wheat [26], but little is known about their physiological role in drought tolerance. Therefore, understanding signal transduction in wheat during drought conditions will be helpful in increasing the pace of molecular breeding of drought-tolerant wheat cultivars.

In this study, we identified two U-box-type ubiquitin E3 ligases in wheat (Triticum aestivum L. 'Keumkang') TaPUB2 and TaPUB3. TaPUB2 and TaPUB3 were characterized in response to abiotic stress. Moreover, the yeast two-hybrid assay and bimolecular fluorescence complementation (BiFC) assay elucidated the heterodimeric complex formed by TaPUB2 and TaPUB3. Finally, we overexpressed TaPUB2 and TaPUB3 in Arabidopsis and showed their phenotypic effects under drought stress condition. Although further studies are needed to elucidate the function of the two heterodimer-forming genes (TaPUB2 and TaPUB3), our study might contribute to future work on understanding the molecular mechanism of TaPUB2/TaPUB3.

\section{Results}

\subsection{Isolation of Drought-Induced PUB Genes}

In a previous report, 213 PUB genes were identified and classified in wheat, according to their functional domain. Among them, 118 genes showed drought- and heat-stressspecific expression patterns [18]. Based on these results, we selected 15 genes that were highly expressed under drought stress conditions to identify the involvement of TaPUBs in the metabolism of drought stress responses (Figure 1A). Phylogenetic analysis revealed five groups, of which two groups consisted of three genes from each subgenome-A, B, and D. Furthermore, RT-PCR was used to examine the expression patterns of $11 \mathrm{U}$-box genes that were expressed under drought conditions, and the results indicated that the expression of two genes (TraesCS5A02G198800.1 and TraesCS2B02G499300.1) was upregulated, while the expression of two genes (TraesCS5D02G210500.1 and TraesCS4B02G371600.1) was downregulated after $6 \mathrm{~h}$ of drought treatment (Figure 1B). Therefore, TraesCS5A02G198800.1 and 
TraesCS2B02G499300.1, named TaPUB2 and TaPUB3, respectively, were selected for further studies. Furthermore, we tried to confirm the transcript levels of TaPUB2 and TaPUB3 in wheat leaf tissues treated with drought stress for different durations $(0,6,12$, and $24 \mathrm{~h})$ (Figure 1C). Compared to TaPUB2 and TaPUB3 levels in the control (0 h), TaPUB2 and TaPUB3 were significantly induced in the leaves after 6 to $24 \mathrm{~h}$ of drought stress treatment.

A
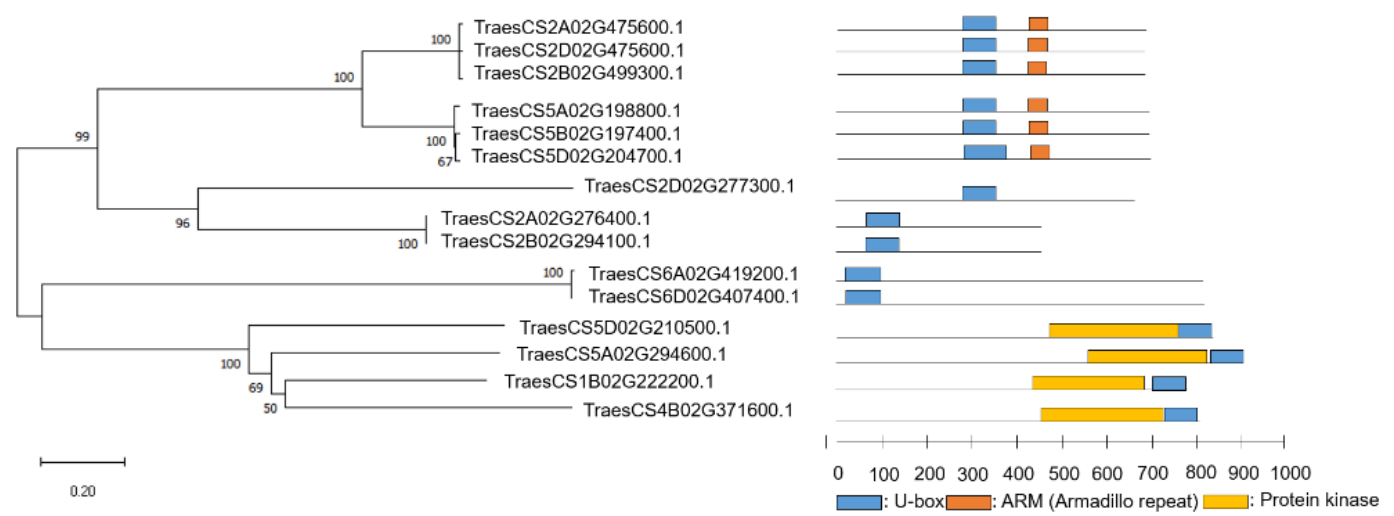

B

0.20

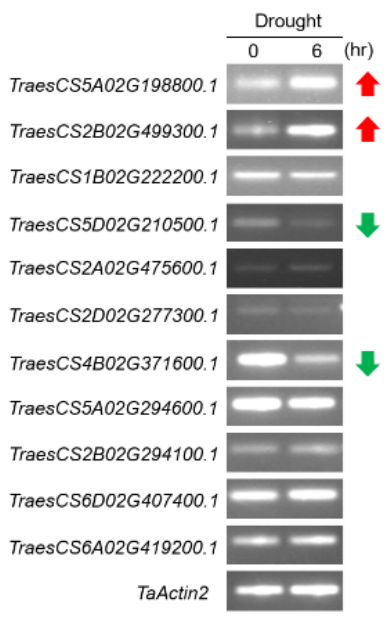

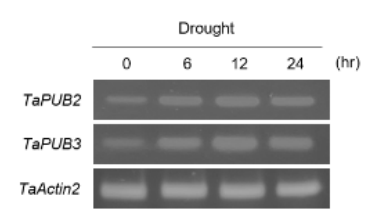

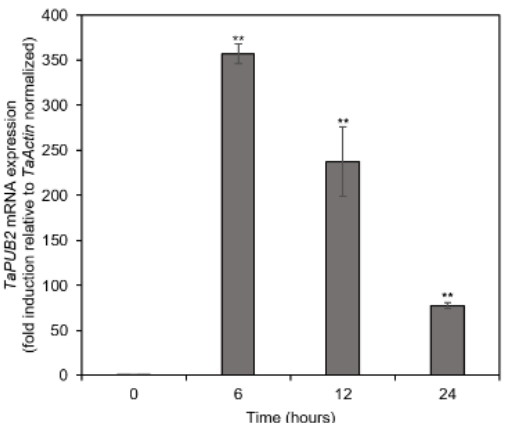

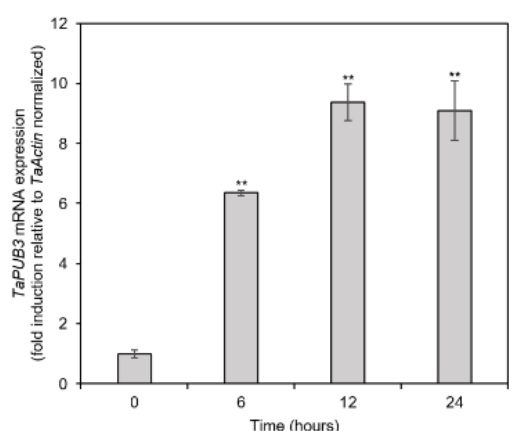

Figure 1. Identification and expression patterns of TaPUB genes. (A) Phylogenetic tree showing deduced protein sequences of 15 TaPUB genes. (on the right) Schematic diagram of full-length TaPUB cDNA. (B) RT-PCR of 11 TaPUB genes in wheat leaf during drought stress treatment (polyethylene glycol (PEG) $(20 \%)$ with different times $(0$ and $6 \mathrm{~h})$ ). Red and green arrows represent the up and downregulation of genes. (C) RT-PCR and qRT-PCR analyses of TaPUB2 and TaPUB3 in wheat leaf tissues treated with drought stress (PEG (20\%) in a time course experiment $(0,6,12$, and $24 \mathrm{~h})$ ). The relative expression levels of genes are presented as the mean \pm SD of three experimental replicates. TaActin 2 was used as the control. Asterisks represent statistically significant differences based on a two-tailed Student's t-test when compared to controls $(0 \mathrm{~h}) ;{ }^{* *} p<0.01$.

\subsection{TaPUB2 and TaPUB3 in Response to Different Abiotic Stresses}

We analyzed the transcript levels of TaPUB2 and TaPUB3 in response to cold stress $\left(4{ }^{\circ} \mathrm{C}\right)$, salt stress $(200 \mathrm{mM} \mathrm{NaCl})$, and ABA $(0.1 \mathrm{mM})$ at $0,6,12$, and $24 \mathrm{~h}$ to determine whether they were upregulated (Figure 2). The expression levels of TaPUB2 and TaPUB3 were highly increased under cold treatment at $6 \mathrm{~h}$ and decreased afterwards. TaPUB2 and TaPUB3 were highly expressed between 6 and $24 \mathrm{~h}$ under salt treatment. However, they were highly expressed only at $12 \mathrm{~h}$ after ABA treatment. 

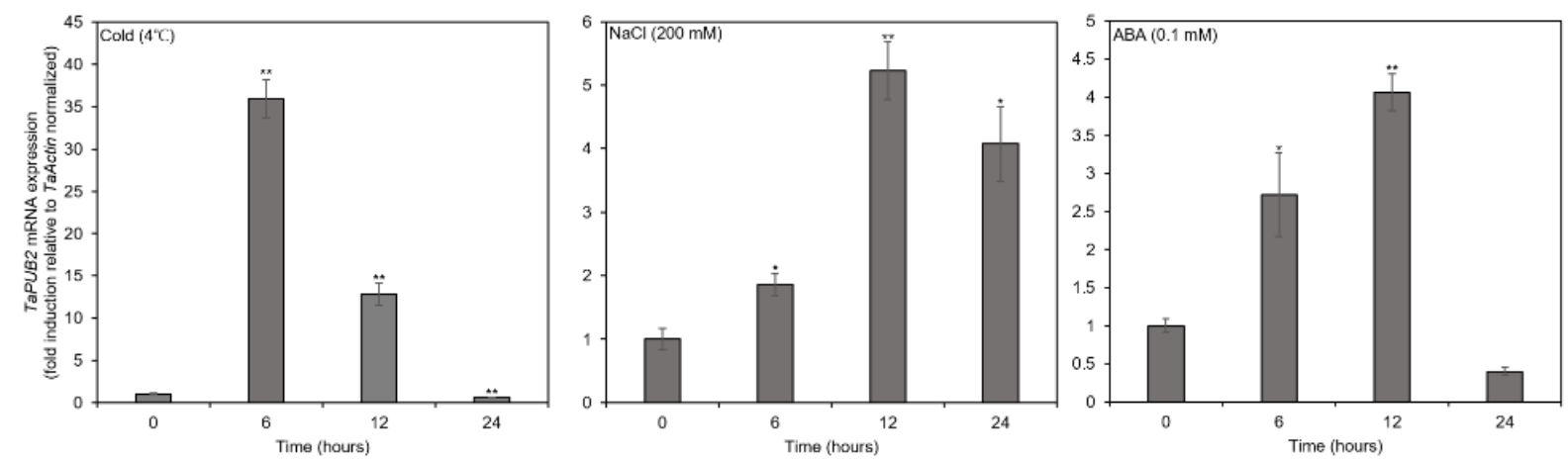

B
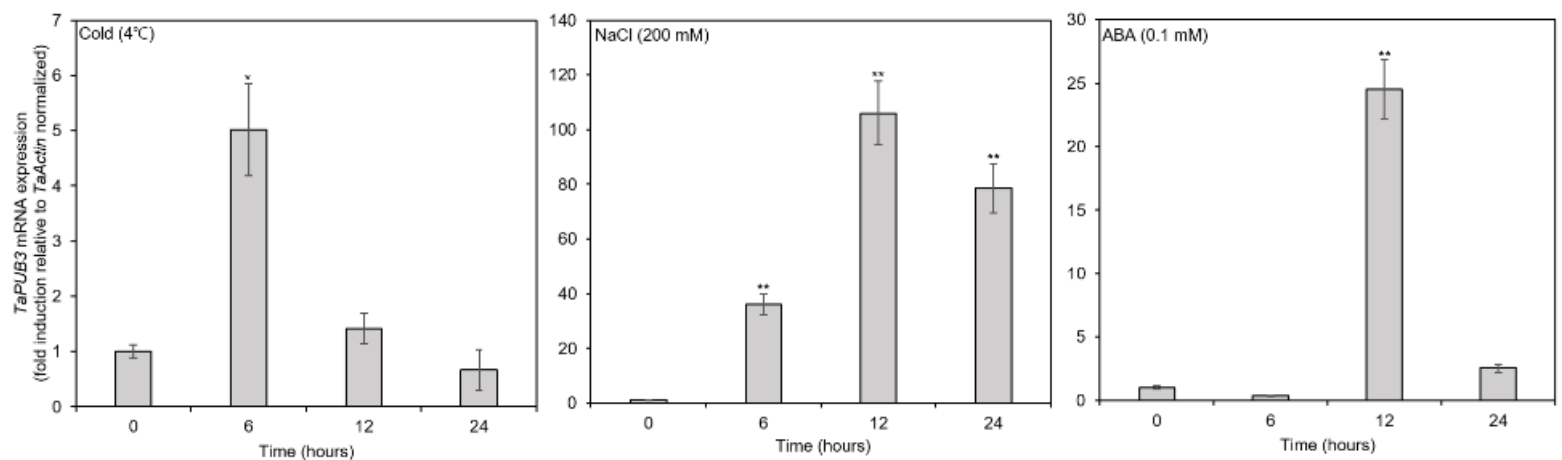

Figure 2. Gene expression patterns of TaPUB2 and TaPUB3 in response to different abiotic stresses (cold $\left(4{ }^{\circ} \mathrm{C}\right)$, salt (200 mM NaCl), and abscisic acid (ABA) $(0.1 \mathrm{mM}))$. (A,B) qRT-PCR analysis of TaPUB2 and TaPUB3 under different types of abiotic stresses in wheat leaf tissues. The TaPUB2 and TaPUB3 mRNA expression levels of the genes are presented as the mean \pm SD of three biological replicates. TaActin 2 was used as the control. Asterisks represent statistically significant differences based on a two-tailed Student's t-test when compared to controls $(0 \mathrm{~h}){ }^{*} p<0.05,{ }^{* *} p<0.01$.

\subsection{Subcellular Localization of TaPUB2 and TaPUB3 Proteins in Wheat Protoplast}

To examine the transient expression of TaPUB2 and TaPUB3, the fluorescence signals of 35S:TaPUB2-GFP and 35S:TaPUB3-GFP were detected, respectively, in wheat protoplast cells using the polyethylene glycol (PEG) transfection system (Figure 3). The 35S:GFP-fused TaPUB2 was targeted to the cytosol and Golgi apparatus (Figure 3A). The 35S:GFP and Golgi apparatus marker (G-rk-CD3-967) were used to confirm the localization of TaPUB2 (Figure 3A,B) [27]. Similarly, the 35S:GFP-fused TaPUB3 was also targeted to the Golgi apparatus (Figure 3B).

\subsection{In Vitro Ubiquitination Assay of TaPUB2 and TaPUB3}

TaPUB2 (TraesCS5A02G198800.1) and TaPUB3 (TraesCS2B02G499300.1) are homologous genes that encode putative E3 ligases with $61 \%$ amino acid sequence similarity in wheat (Figure 4A). Both proteins contain a U-box and an Armadillo (ARM) repeat domain in the central regions. Moreover, most U-box-containing proteins have been shown to possess E3 ligase activity. We performed an ubiquitination assay using MBP-tagged recombinant proteins (pMAL-c5x-TaPUB2 and pMAL-c5x-TaPUB3). The analysis showed that MBPfused TaPUB2 and TaPUB3 generated poly ubiquitinated chains in the presence of E1, E2, and $\mathrm{Ub}$ (Figure $4 \mathrm{~B}$ ). Furthermore, we generated mutants-MBP-TaPUB2 ${ }^{\mathrm{C} 323 \mathrm{~A}}$ and MBPTaPUB3 ${ }^{\mathrm{C} 325 \mathrm{R}}$ to confirm the ubiquitination activity of the U-box domain, where cysteine-323 and cysteine-325 were replaced by alanine and arginine, respectively. However, no poly ubiquitinated chains were detected in the absence of E1, E2, E3, or mutated TaPUB2 and TaPUB3. 
A

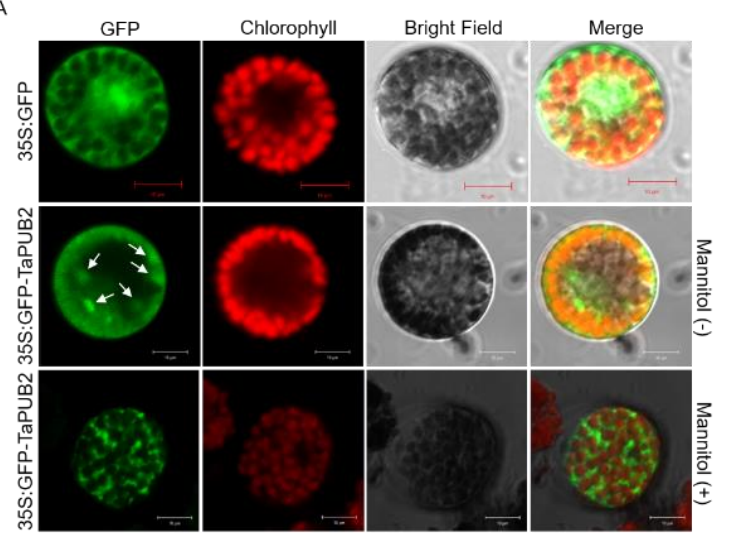

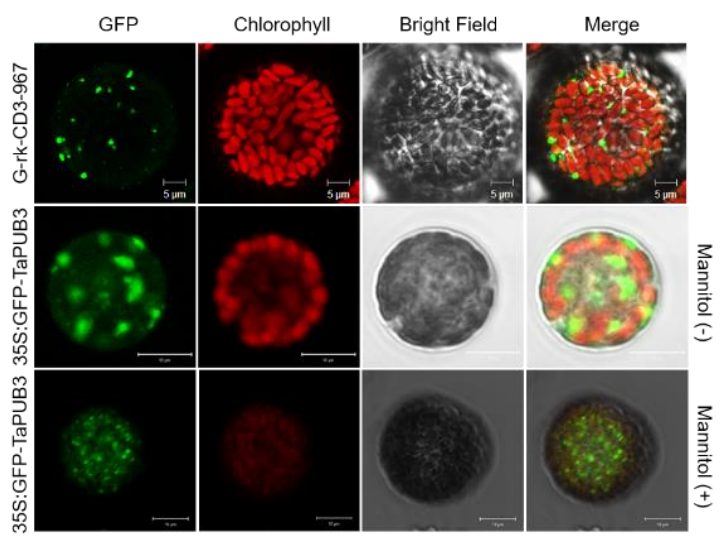

Figure 3. Subcellular localization of TaPUB2 and TaPUB3. Subcellular localization of (A) 35S:GFP-TaPUB2 and (B) 35S:GFPTaPUB3 in wheat protoplasts. 35S:GFP and G-rk-CD3-967 were used as controls. A confocal laser scanning microscope was used to detect the fluorescence signal.

A
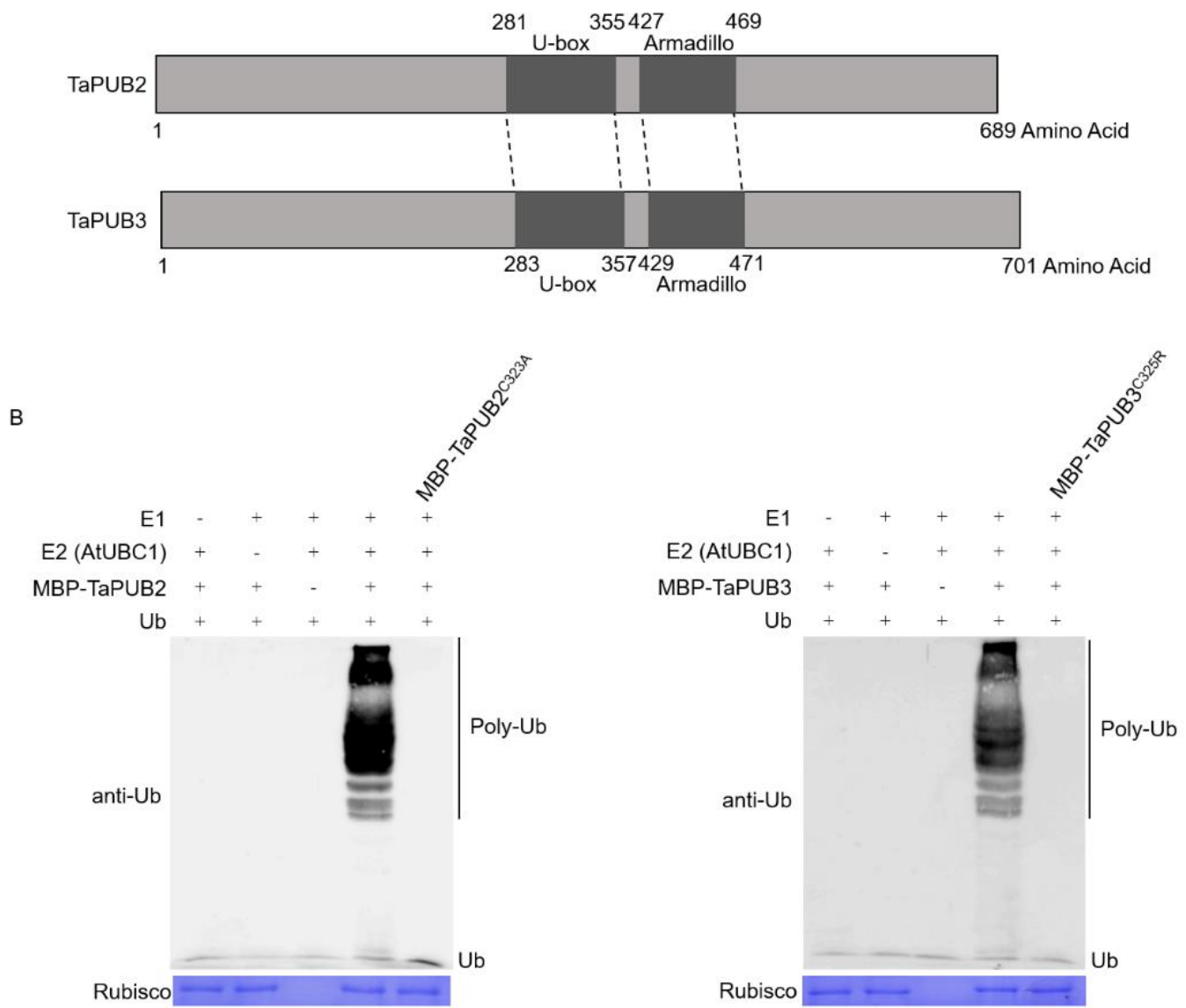

Figure 4. In vitro E3 ligase activity of TaPUB2 and TaPUB3. (A) Schematic diagram of full-length TaPUB2 and TaPUB3 proteins. The solid bar depicts the protein length. The U-box and Armadillo repeat domain are shown as dark gray bars. (B) The ubiquitination reaction contains E1 (human), E2 (AtUBC1), E3 (MBP-TaPUB2, MBP-TaPUB2C323A, MBP-TaPUB3, and MBP-TaPUB3 ${ }^{\mathrm{C} 325 \mathrm{R}}$ ), and ubiquitin. Polyubiquitin chains are visible by immunoblotting with a ubiquitin antibody. $(+)$ means presence, and (-) means absence. 


\subsection{TaPUB2 and TaPUB3 Form Heterodimers}

The U-box/RING type E3 ligase often has a heterodimeric form, which has significant E3 ligase activity $[28,29]$. We performed yeast co-transformation to determine whether TaPUB2 and TaPUB3 form a complex. The full-length ORFs of TaPUB2 and TaPUB3 were cloned into the pGBKT7 (BD) and pGADT7 (AD) vectors, respectively, and co-transformed into AH109 yeast strain cells. Transformed yeast cells were placed onto D-aspartate oxidase $\mathrm{DDO}$ (SD/-Lue/-Trp) and QDO/X (SD/-Lue/-Trp/-His/-Ade/X-a-gal) growth media. The results showed that co-transformed TaPUB2 and TaPUB3 could interact with each other and form a heterodimer in quadruple dropout QDO/X media (Figure 5A). Next, we performed an in vitro pull-down assay using His-tagged TaPUB2 and MBP-tagged TaPUB3. The in vitro pull-down assay detected TaPUB3 protein, which was pulled down by TaPUB2 (Figure 5B). Furthermore, we examined the possible mechanisms by which TaPUB2 interacts with TaPUB3 using BiFC assays in planta. Both nYFP-TaPUB3 and cYFPTaPUB2 were co-localized in the cytoplasm of the wheat protoplast cells (Figure 5C). These results implied that TaPUB2 and TaPUB3 bonded to each other to form a heterodimeric complex in yeast and plants.

A

\begin{tabular}{|l|l|l|}
\multicolumn{3}{|c|}{ SD/-Leu/-Trp } \\
\hline AD AD & pGADT7 & TaPUB3 \\
\cline { 1 - 1 } & & \\
\cline { 1 - 1 } pGBKT7 & \\
\cline { 1 - 1 } TaPUB2 & \\
\hline
\end{tabular}

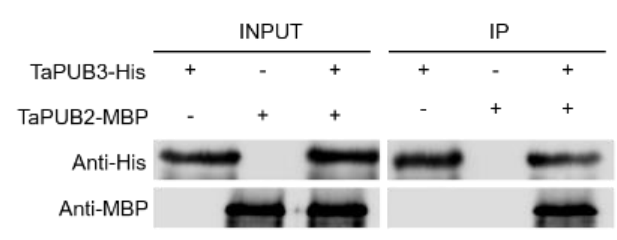

\begin{tabular}{|l|l|l|}
\multicolumn{3}{c|}{ SD/-His/-Leu/-Trp/X } \\
\hline PDA & pGADT7 & TaPUB3 \\
\cline { 1 - 1 } PGBKT7 & \\
\cline { 1 - 1 } TaPUB2 & \\
\hline
\end{tabular}

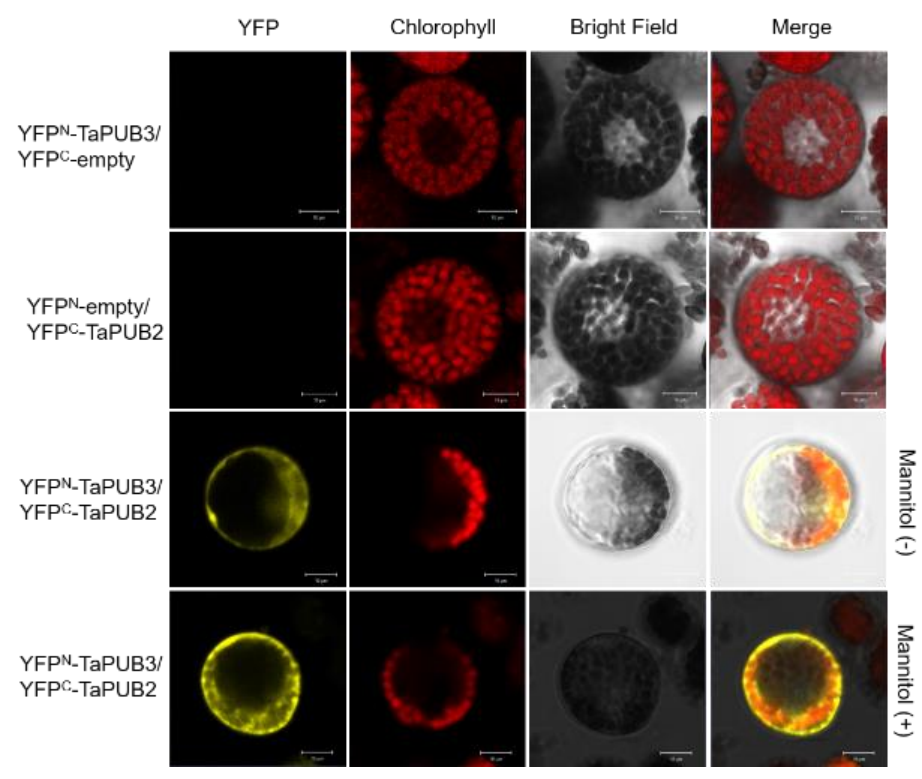

Figure 5. Heterodimeric complex formation of TaPUB2 and TaPUB3. (A) Yeast two-hybrid assay with TaPUB2 and TaPUB3. Full-length cDNA fragments encoding TaPUB2 and TaPUB3 were fused to sequences encoding GAL4 DNA-binding domain (BD) and GAL4 activation domain (AD) in pGBKT7 and pGADT7, respectively. Each construction was co-transformed into AH109 yeast strain in SD/-Leu/-Trp and SD/-Lue/-Trp/-His/-Ade/X-a-gal media. (B) In vitro pull-down assay of TaPUB3-His protein and MBP-TaPUB2 protein. (C) BiFC assay of TaPUB2 and TaPUB3 interactions using protoplast cells. TaPUB2 was fused into $C$-terminal YFP, and TaPUB3 was fused into $N$-terminal YFP. A confocal laser scanning microscope was used to detect the fluorescence signal.

\subsection{Overexpression of TaPUB2 and TaPUB3 Confers Tolerance to Drought Stress in Arabidopsis Plants}

To evaluate the molecular function of TaPUB2 and TaPUB3 under drought conditions, we developed TaPUB2- and TaPUB3-overexpressing Arabidopsis plants, respectively (Figure S1). Heterologous overexpression of TaPUB2 and TaPUB3 led to a higher percentage of seed germination rate than that of the wild type (WT) upon treatment with different concentrations of mannitol (200 and $400 \mathrm{mM}$ ) on a half-strength MS medium (Figure 6C,D). Similarly, we measured the root lengths in transgenic and WT plants that had been exposed to different concentrations of mannitol (200 and $400 \mathrm{mM}$ ) for 4 days after transferring 4-day-old seedlings onto 1/2 MS media. The root lengths of TaPUB2 (OE1 and OE2) and 
TaPUB3 (OE1 and OE2) transgenic plants significantly increased compared with that of the $\mathrm{WT}$, while the root length under normal growth conditions did not differ clearly between the two groups (Figure 6A,B).
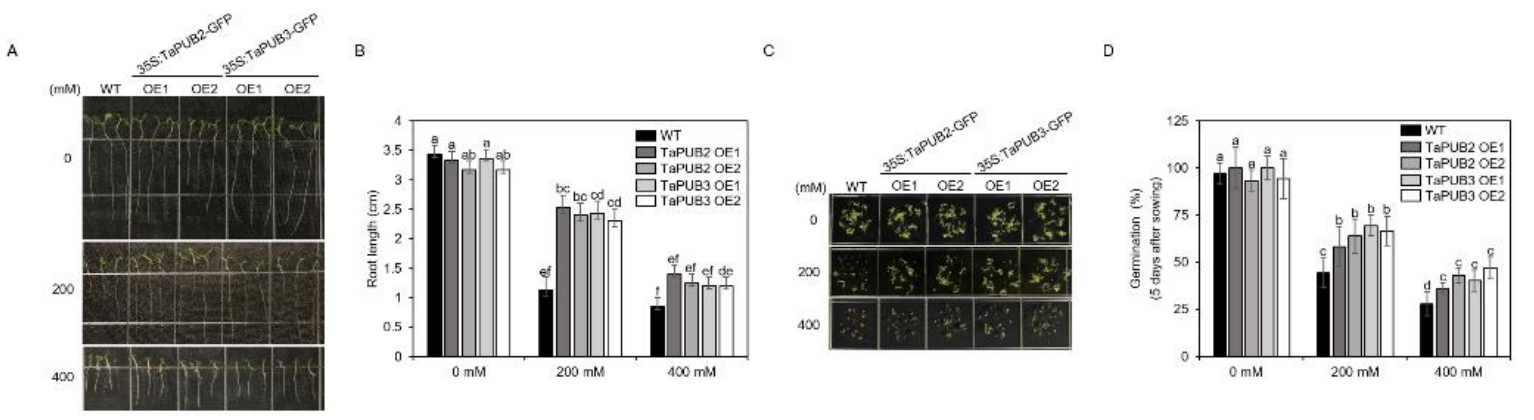

E
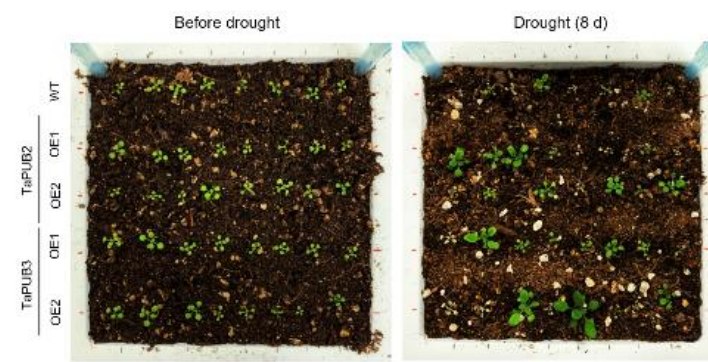

Drought (12 d)

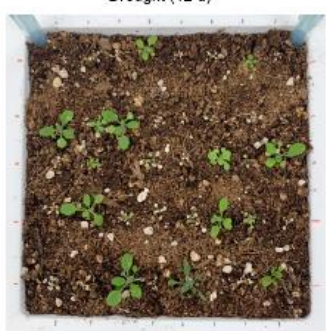

Drought (15 d)

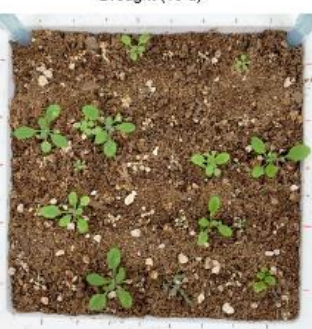

Re-watering ( 5 d)

G
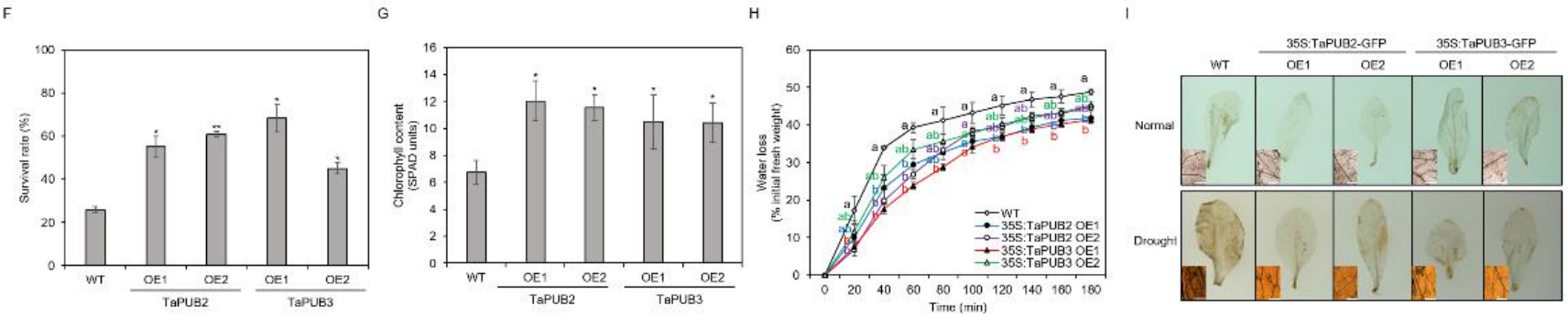

Figure 6. Phenotypes of WT and 35S:TaPUB2 and 35S:TaPUB3 overexpression plants in response to drought treatment. $(\mathbf{A}, \mathbf{B})$ Root length of the indicated genotypes. Four-day-old seedlings were transferred from 1/2 MS to 1/2 MS medium previously infused with different concentrations of mannitol (200 and $400 \mathrm{mM}$ ). Photographs were taken 4 days after the transfer. (C,D) Germination rate of TaPUB2- and TaPUB3-overexpressing plants in MS and mannitol (200, $400 \mathrm{mM}$ )containing MS media. (E) TaPUB2, TaPUB3, and WT grown under drought stress. After planting in soil, seedlings were not watered for 2 weeks and then re-watered for 1 week. (F) Survival rates (\%) under drought conditions were determined as the number of visibly green plants after rehydration. (G) Total chlorophyll content was measured in WT and overexpressing plants after recovery. $(\mathbf{H})$ Comparison of the rate of water loss from detached rosettes between WT and overexpressing plants. (I) $\mathrm{H}_{2} \mathrm{O}_{2}$ content in Arabidopsis under normal conditions and drought treatment, with 3,3-diaminobenzidine staining assay of rosette leaves of WT and TaPUB2 and TaPUB3-overexpressing lines. Values are mean $\pm \mathrm{SD}, \mathrm{n}=3$. ${ }^{*}$ Indicates significant difference between TaPUB2 or TaPUB3 plants and WT control based on the ANOVA $\left(* 0.01 \leq p<0.05,{ }^{* *} p<0.01\right)$, using the Duncan's multiple range test (DMRT). Different letters indicate significant differences ( $p$-value 0.05$)$ among the genotypes under the same treatment. 
The performance of soil grown TaPUB2 and TaPUB3 transgenic seedlings was examined under water deprivation conditions in the soil. Under normal conditions, plants did not exhibit any morphological differences between the WT and OE lines. After 15 days of normal growth conditions, the plants were deprived of water for 14 days and then watered normally (Figure 6E). TaPUB2 and TaPUB3-overexpressing plants showed a significantly higher survival rates (by 2.3-fold) compared with that of the WT plants (Figure 6F). Furthermore, under drought stress conditions, the chlorophyll content of the transgenic plants was 1.5-fold higher than that of the WT plants (Figure 6G). In contrast, TaPUB2 and TaPUB3-overexpressing plants were found to have a lower water loss rate than that of the WT plants (Figure $6 \mathrm{H}$ ).

Additionally, the accumulation of ROS in TaPUB2 and TaPUB3 transgenic lines and WT plants was analyzed using 3,3-diaminobenzidine (DAB) staining and nitroblue tetrazolium (NBT) analysis. Under drought stress conditions, the WT plants accumulated more ROS than the OE lines (Figure 6I and Figure S2). These results strongly suggested that TaPUB2 and TaPUB3 function in the same signaling pathway in their plant responses to drought stress.

\subsection{Transcriptional Analysis of Drought Stress Responsive Genes in TaPUB2 and TaPUB3-Overexpressing Plants}

To verify the mRNA level changes of several drought stress-induced genes in TaPUB2 and TaPUB3 transgenic plants, we performed qRT-PCR under drought (air drying) conditions. The overexpression of TaPUB2 and TaPUB3 in Arabidopsis plants showed a tolerant phenotype under drought conditions (Figure 6). Therefore, to evaluate the transcript expression of drought-induced genes, we examined 13 drought-responsive genes, including AtRD29A (AT5G52310), AtRD22 (AT5G25610), AtRD20 (AT2G33380), AtDREB1B (AT4G25490), AtDREB2A (AT5G05410), AtNCED3 (AT3G14440), AtERD1 (AT5G51070), AtABF3 (AT4G34000), AtAFP1 (AT1G69260), AtPP2CA (AT3G11410), AtHAI1 (AT5G59220), AtABI5 (AT2G36270), and AtKIN2 (AT2G02800) [30-34]. Statistical analysis of these genes' mRNA expression levels revealed a significantly increased transcription level when compared to their WT counterparts during drought conditions $(5 \mathrm{~h})$, while some of the genes in fold induction level could be detected under control conditions (Figure 7). Furthermore, $G$, $T$, and $G \times T$ had a significant impact on the expression of these genes (Table S2). These results revealed that TaPUB2 and TaPUB3 positively regulated the transcript levels of these genes under drought conditions. 

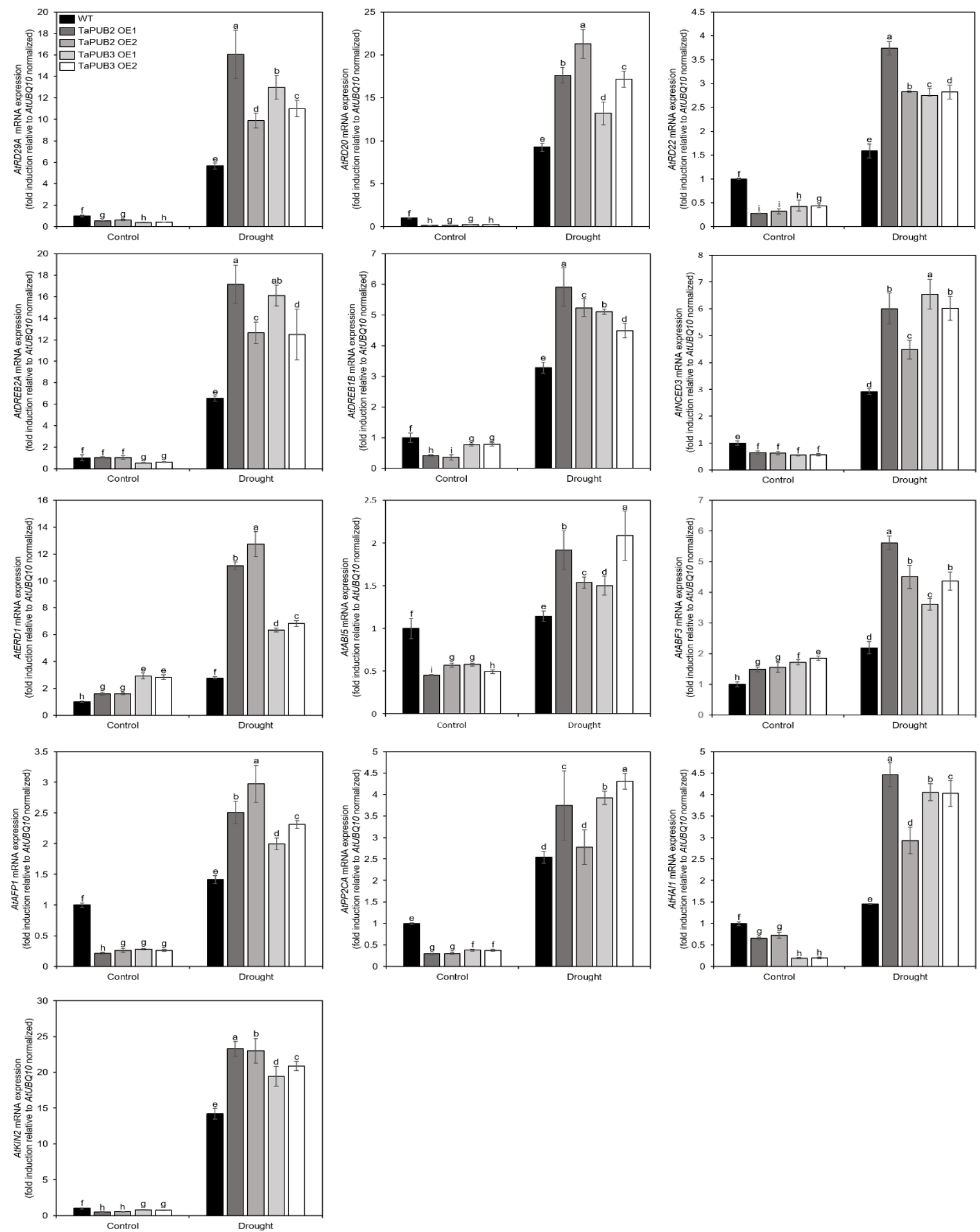

Figure 7. Real-time qRT-PCR analysis of drought-stress related maker genes. For dehydration treatment, the lid of the dish was opened under light for $5 \mathrm{~h}$ at room temperature. The induction patterns of various ABA- and/or drought-responsive genes (RD29A, RD20, RD22, DREB2A, DREB1B, NCED3, ERD1, ABI5, ABF3, AFP1, PP2CA, HAI1, and KIN2) were analyzed using qRT-PCR. Data represent the fold induction of each gene under dehydration $(5 \mathrm{~h})$ relative to the gene level of the control treatment $(0 \mathrm{~h})$. The mean values from three independent technical replicates were normalized to the levels of the internal control, UBC10 mRNA. Different letters indicate significant difference at $(p<0.05)$ between the WT and 35S:TaPUB2 and 35S:TaPUB3 Arabidopsis transgenic plants. 


\section{Discussion}

Although the role of PUB E3 ligases has been reported in many abiotic and biotic stress conditions in various plant species, their molecular and metabolic functions in wheat remain unclear, particularly under abiotic stress conditions $[19,35,36]$, since their biological and molecular study has only been in the initial stages in wheat. In this study, we identified functional analysis of two PUB E3 ligases, TaPUB2, and TaPUB3, in wheat (Figures 1A and 4A). The transcriptional profiles of TaPUB2 and TaPUB3 were confirmed by the results of their response to abiotic stresses in wheat; the expression of both TaPUB2 and TaPUB3 was highly upregulated under abiotic stresses-drought, cold, salt, and ABA (Figures 1 and 2). Furthermore, the sequence similarity index (61\%) and domain structure analysis revealed the presence of a conserved domain (ARM and U-box) and other residues, indicating that TaPUB2 and TaPUB3 were highly conserved (Figure 4A). Subcellular localization analysis revealed that TaPUB2 and TaPUB3 were localized in the Golgi apparatus (Figure 3A), indicating that they may have been involved in various intercellular mechanisms or functions in wheat.

Several studies have reported that wheat U-box proteins have multiple functions in response to abiotic stresses. For example, the U-box protein TaPUB1 improved salt and drought stress tolerance in Nicotiana benthamiana [13]. TaPUB15 overexpression resulted in enhanced root growth and development and an increased resistance to salt stress in rice [37]. E3 ubiquitin ligase functions in response to abiotic stress and is dependent on the ABA pathway [38]. Similarly, TaPUB1 and TaPUB15 E3 ligases were shown to be highly expressed in transgenic plants in response to $\mathrm{ABA}$ signaling and enhance tolerance to salt stress $[13,37]$. In our study, the transcription of TaPUB2 and TaPUB3 was significantly induced by drought stress and highly upregulated by ABA, cold, and salt stresses (Figures 1 and 2), suggesting that TaPUB2 and TaPUB3 may be involved in drought, cold, and salt stress responses in an ABA-dependent manner. The bZIP transcription factor (TFs) are well known drought stress response pathways. bZIPs members are related in post-translational modification, such as phosphorylations/de-phosphorylation events [39]. bZIP TFs, including nine subfamily member ABREs/ABFs, have existed in Arabidopsis. Among them, ABF1, AREB1/ABF2, AREB2/ABF3, and ABF4 have been phosphorylated by SnRK2s (Snf1-related protein kinase) and regulate the expression of ABA-dependent drought signaling pathways [40]. In this study two ABA-dependent drought induced genes, such as AtABI5 and AtABF3, were up-regulated in response to the TaPUB2 and TaPUB3-overexpressing in plants growing drought condition (Figure 7). Moreover, when there was a water deficit condition, ABA caused stomatal closure, reducing water loss through transpiration [41]. These results were consistent with reducing the water loss rate in TaPUB2 and TaPUB3-overexpressing plants (Figure 6H). However, further work is needed to understand the ABA-dependent response and other abiotic stress mechanisms in transgenic plants.

A previous study [26] demonstrated that heterologous overexpression of TaPUB1 positively regulates post-germination plant growth under drought stress (PEG 6000). To study the physiological function of TaPUB2 and TaPUB3 in plant growth as well as drought tolerance, we generated transgenic Arabidopsis plants using the floral dipping method (Figure S1). Water deficit significantly delayed the onset of seed germination rate. Some of E3 ligase, which contains the U-box domain, have important roles in seed germination under the drought stress [42]. Similarly, under drought stress conditions, the seed germination rate of TaPUB2 and TaPUB3 overexpression plants was much greater than that of WT plants (Figure 6C,D). Moreover, the root development of the TaPUB2 and TaPUB3 transgenic lines have also longer than WT under osmotic stress conditions (Figure 6A,B). Water deficiency has a considerable impact not only during the seedling stage but also during the vegetative stages [26]. Under drought stress, TaPUB2 and TaPUB3 transgenic plants showed improved survival rates and robust phenotypes, such as green leaves and high chlorophyll content (Figure 6). These findings indicate that U-box type E3 ligases were 
involved in the regulation of plant adaptation mechanisms during harsh environments, such as drought.

When the amount of available soil water is severely limited, the first option for plants induced accumulation of ROS and close their own stomata [8]. Drought stress causes oxidative stress by increasing ROS, such as ${ }^{1} \mathrm{O}_{2}$ (singlet oxygen), $\mathrm{O}_{2}{ }^{-}$(superoxide radical), $\mathrm{HO} \bullet$ (hydroxyl radical), and $\mathrm{H}_{2} \mathrm{O}_{2}$ (hydrogen peroxide), all of which are highly reactive and contribute to drought stress [43]. Excess ROS are scavenged or detoxified by an efficient antioxidative system that includes both nonenzymic and enzymic antioxidants, such as superoxide dismutase (SOD), catalase (CAT), and ascorbate peroxidase (APX) [44]. Previously, [45] it was demonstrated that drought stress resistance in VyP5CR transgenic Arabidopsis revealed less efficient scavenging of $\mathrm{H}_{2} \mathrm{O}_{2}$ as compared WT lines. In the present study, we observed that TaPUB2 and TaPUB3 transgenic line have a more effective antioxidant defense system and less accumulation of ROS (Figure 6I and Figure S2). These findings revealed that TaPUB2 and TaPUB3 were involved in mechanisms that protect cells during drought stress.

The predicted U-box protein has a domain similar to that of the RING-finger protein, despite the loss of hallmark and histidine residue [46,47], and is found in combination with other domains, such as ARM (armadillo) repeats, Ser/Thr kinase domain, WD40 repeats, or tetratricopeptide (TPR) domain, or peptidyl-prolyl isomerase [48]. E3 ligase, which contains a U-box domain, performs ubiquitination upon forming a complex with the activating enzyme E1 and conjugating enzyme E2 [49]. We incorporated a single amino acid mutation in TaPUB2 and TaPUB3 by substituting cysteine at the 323 rd position with alanine and cysteine at the 325th position with arginine, respectively, in the U-box domain. A previous report demonstrated that PUB E3 ligase activity depends on cysteine residues [15]. Thus, the mutations in TaPUB2 and TaPUB3 result in catalytically inactive forms in the presence of E1, E2, and ubiquitin (Figure 4B). These findings showed that TaPUB2 and TaPUB3 have E3 ligase activities, and they require the U-box domain to perform ubiquitination.

Recent studies have shown that several E3 ligases play combinatory roles, suggesting that they form heterodimers [39,40]. Furthermore, [50] identified homologous OsPUB2 and OsPUB3 proteins degrade rapidly upon forming a heterodimer. Therefore, we tested whether TaPUB2 interacts with TaPUB3 using the yeast-two hybrid assay (Figure 5A). Moreover, we confirmed the interaction between TaPUB2 and TaPUB3 using BiFC assays (Figure 5B). Interestingly, the TaPUB2/TaPUB3 protein complex occurred in the cytoplasm, whereas TaPUB2 was transiently expressed, and TaPUB3 was localized in the Golgi apparatus (Figure 3). The spatial differences in the expression of complex proteins could also be observed in other studies. For example, the cytoplasm and nucleus-localized Histone H2B mono-ubiquitination enzyme (TaHUB2) physically interacts with the nuclear proteins, such as TaELF7, in wheat [51]. OsSADR1 interacts with and regulates the chloroplast-localized protein OsPIPIN in the cytoplasm [8]. Therefore, TaPUB3 might be translocated from the Golgi apparatus to the cytoplasm, thus interacting with TaPUB2 to form a heterodimeric complex.

\section{Materials and Methods}

\subsection{Plant Material and Growth Conditions}

The seeds of a wheat variety [Triticum aestivum L. 'Keumkang' (Korea RDA Accession No. IT213100)] were germinated and grown in a growth chamber $\left(25^{\circ} \mathrm{C}\right.$ with $60 \%$ relative humidity and photoperiod of $16 \mathrm{~h}$ light intensity) on mesh supported in plastic containers with one-half concentration of MS (Murashige and Skoog) liquid media. The 14-dayold plants were treated with abiotic stresses, including drought (20\% PEG 6000), salt $(200 \mathrm{mM})$, cold $\left(4^{\circ} \mathrm{C}\right)$, and ABA $(0.1 \mathrm{mM})$. Leaf tissues were collected at $0,6,12$, and $24 \mathrm{~h}$ following stress treatment. Samples were immediately frozen in liquid nitrogen for further experiment. 


\subsection{Gene Cloning and Phylogeny Analysis}

PUB protein sequences were obtained from a previous study by [18]. The ORFs of TaPUB2 (TraesCS5A02G198800.1) and TaPUB3 (TraesCS2B02G499300.1) were amplified using primer sets designed based on the wheat reference sequence Ensembl Plants (https://plants.ensembl.org/index.html (accessed on 16 December 2021)). i-pfu DNA polymerase (iNtRON Biotechnology, Cat: 25181, Seongnam, Gyeonggi, Korea) and primers were used for PCR amplification (Table S1). TaPUB2 and TaPUB3 were cloned and sequenced into the pCR8/GW/TOPO vector (Invitrogen, Cat: K250020, Carlsbad, CA, USA). MEGA-X software was used to generate a phylogenetic analysis [52].

\subsection{Gene Expression Studies}

RNA extraction, cDNA conversion, primer design, and qRT-PCR was used to analyze the transcript expression patterns of the putative genes and the results were estimated using the delta-delta CT method [51,53]. qRT-PCR experiments were performed from three independent biological replicates.

\subsection{Subcellular Localization}

To examine the subcellular localization of TaPUB2 and TaPUB3, two genes were cloned into the GFP vector (pMDC43) and BiFC vector (pGTQL1211 and pGTQL1221) using LR reaction (Invitrogen, Cat: 11791020, Carlsbad, CA, USA), respectively. The resulting constructs were used for transient assays using wheat protoplasts transfected with polyethylene glycol [54].

\subsection{Ubiquitination Assay}

To perform the E3 ligase activity of TaPUB2 and TaPUB3, each gene was cloned into the MBP-tagged vector (pMAL-c5x). An in vitro ubiquitination experiment was carried out using a previously described protocol $[10,55]$.

\subsection{Yeast Two-Hybrid Assay}

The Matchmaker GAL4 bases two-hybrid system was used for the yeast two-hybrid assays (Clontech, Cat: 630489, Palo Alto, CA, USA). The full-length sequences of TaPUB2 and TaPUB3 were recombined into the pGDAT7 (including activation domain (AD)) and pGBKT7 (including binding domain (BD)), respectively. TaPUB2, TaPUB3, and empty vector were co-transformed and grown in DDO medium after being transformed into the AH109 yeast strain. Each clone was cultured in DDO broth for 5 days before being spotted on a QDO medium to test for protein-protein interactions.

\subsection{Pull-Down Assay}

To determine the PUB2 physical interaction with TaPUB3, MBP-tagged TaPUB2 and His-tagged TaPUB3 proteins were expressed in Escherichia coli (strain BL21). The pull-down assay was used for His Protein Interaction Pull-Down Kit (Invitrogen, Cat: 21277, Carlsbad, CA, USA), as previously described by [54].

\subsection{Generation of Transgenic Arabidopsis Plants}

For overexpression of TaPUB2 and TaPUB3 in Arabidopsis, the ORF fragments that had been amplified were subcloned into pMDC43 vectors. The resulting plasmids were introduced into pMDC43 binary vectors to obtain the 35S:TaPUB2-GFP and 35S:TaPUB3-GFP constructs that were used for Agrobacterium (GV3101)-mediated transformation in Arabidopsis (ecotype Columbia-0) using the floral dipping method [56]. All experiments were carried out on homozygous T3 generation plants. For each assay, at least two independent transgenic lines were used. 


\subsection{Dehydration and Drought Tolerance}

Overexpression lines and WT seeds were germinated and grown for 15 days at $25^{\circ} \mathrm{C}$ in a growth chamber $\left(25^{\circ} \mathrm{C}\right.$ with $60 \%$ relative humidity and photoperiod of $16 \mathrm{~h} \mathrm{light}$ intensity). Some seedlings were dehydrated, while others were subjected to drought treatment by stopping irrigation for 14 days. The rosette leaves of 14-day-old seedlings of each transgenic line were placed on filter papers and allowed to dry for up to $5 \mathrm{~h}$ for dehydration analysis. To determine the rate of water loss, the fresh weight of each sample was measured every $20 \mathrm{~min}$. To detect $\mathrm{H}_{2} \mathrm{O}_{2}$, the leaves were incubated for $4 \mathrm{~h}$ in a $1 \mathrm{mg} / \mathrm{mL}$ DAB solution (Sigma-Aldrich, Cat: D8001, St Louis, MO, USA). Following the incubation period, the leaf samples were immersed in a bleaching solution (ethanol: acetic acid: glycerol, 3:1:1) and boiled for $15 \mathrm{~min}$ at $95^{\circ} \mathrm{C}$ [50].

\subsection{Statistical Analysis}

All experimental data were the means of at least three separate replicates, and statistical analysis was carried out with Microsoft Excel 2016. (Microsoft, Seattle, WA, USA). For comparisons between two analyzed populations and among three or more populations, the Student's t-test and Duncan's multiple range test from one-way and two-way analysis of variance (ANOVA) were used to determine if the differences were statistically significant at $p$-values $<0.05$.

\section{Conclusions}

In the present study, the molecular function of TaPUB2 and TaPUB3, including their expression patterns, subcellular localization, and E3 ligase activity was elucidated. Two proteins directly interact with one another and form heterodimeric complexes (TaPUB2/TaPUB3). Furthermore, TaPUB2 and TaPUB3-overexpressing Arabidopsis displayed a resistance phenotype under the drought condition (media and soil) and a lesser rate of ROS accumulation, respectively. These findings suggest that the two putative U-box E3 ligases, TaPUB2 and TaPUB3, are involved in the response to abiotic stresses, especially drought. However, studying double mutants or transgenic wheat lines would be helpful to further understand the genetic mechanisms involved in drought tolerance.

Supplementary Materials: The following are available online at https:/ / www.mdpi.com/article/ $10.3390 /$ ijms222413658/s1.

Author Contributions: J.H.K., M.S.K., D.Y.K. and Y.W.S. conceived and designed the experiments; J.H.K., M.S.K., D.Y.K. and J.N.A. performed the experiments; and J.H.K., M.S.K., D.Y.K., J.N.A. and Y.W.S. analyzed the data and wrote the paper. All authors have read and agreed to the published version of the manuscript.

Funding: This research was funded by the Korea University and Basic Science Research Program through the National Research Foundation of Korea (NRF), funded by the Ministry of Science, ICT and Future Planning, grant number (2017R1D1A1B06030349 and 2019R1I1A1A01059968).

Institutional Review Board Statement: Not applicable.

Informed Consent Statement: Not applicable.

Data Availability Statement: This research did not report any data.

Conflicts of Interest: The authors declare no conflict of interest.

\section{References}

1. Vij, S.; Tyagi, A.K. Emerging Trends in the Functional Genomics of the Abiotic Stress Response in Crop Plants. Plant Biotechnol. J. 2007, 5, 361-380. [CrossRef] [PubMed]

2. Yoon, J.S.; Seo, Y.W. BdERF96 Interacts with BdASR1 to Specifically Respond to Drought and Oxidative Stress in Brachypodium Distachyon. J. Plant Biochem. Biotechnol. 2021, 30, 287-296. [CrossRef] 
3. Giraldo, P.; Benavente, E.; Manzano-Agugliaro, F.; Gimenez, E. Worldwide Research Trends on Wheat and Barley: A Bibliometric Comparative Analysis. Agronomy 2019, 9, 352. [CrossRef]

4. Mwadzingeni, L.; Shimelis, H.; Dube, E.; Laing, M.D.; Tsilo, T.J. Breeding Wheat for Drought Tolerance: Progress and Technologies. J. Integr. Agric. 2016, 15, 935-943. [CrossRef]

5. Zhao, Y.; Cheng, X.; Liu, X.; Wu, H.; Bi, H.; Xu, H. The Wheat MYB Transcription Factor TaMYB31 Is Involved in Drought Stress Responses in Arabidopsis. Front. Plant Sci. 2018, 9, 1426. [CrossRef] [PubMed]

6. Wang, J.; Li, Q.; Mao, X.; Li, A.; Jing, R. Wheat Transcription Factor TaAREB3 Participates in Drought and Freezing Tolerances in Arabidopsis. Int. J. Biol. Sci. 2016, 12, 257-269. [CrossRef] [PubMed]

7. Zhang, N.; Yin, Y.; Liu, X.; Tong, S.; Xing, J.; Zhang, Y.; Pudake, R.N.; Izquierdo, E.M.; Peng, H.; Xin, M.; et al. The E3 Ligase TaSAP5 Alters Drought Stress Responses by Promoting the Degradation of DRIP Proteins. Plant Physiol. 2017, 175, 1878-1892. [CrossRef]

8. Zhou, S.; Sun, X.; Yin, S.; Kong, X.; Zhou, S.; Xu, Y.; Luo, Y.; Wang, W. The Role of the F-Box Gene TaFBA1 from Wheat (Triticum aestivum L.) in Drought Tolerance. Plant Physiol. Biochem. 2014, 84, 213-223. [CrossRef]

9. Friso, G.; Van Wijk, K.J. Posttranslational Protein Modifications in Plant Metabolism. Plant Physiol. 2015, 169, 1469-1487. [CrossRef]

10. Park, Y.C.; Chapagain, S.; Jang, C.S. A Negative Regulator in Response to Salinity in Rice: Oryza sativa Salt-, ABA- and Drought-Induced Ring Finger Protein 1 (OsSADR1). Plant Cell Physiol. 2018, 59, 575-589. [CrossRef]

11. Chen, L.; Hellmann, H. Plant E3 Ligases: Flexible Enzymes in a Sessile World. Mol. Plant 2013, 6, 1388-1404. [CrossRef]

12. Ohi, M.D.; Vander Kooi, C.W.; Rosenberg, J.A.; Chazin, W.J.; Gould, K.L. Structural Insights into the U-Box, a Domain Associated with Multi-Ubiquitination. Nat. Struct. Biol. 2003, 10, 250-255. [CrossRef]

13. Zhang, M.; Zhang, G.Q.; Kang, H.H.; Zhou, S.M.; Wang, W. TaPUB1, a Putative E3 Ligase Gene from Wheat, Enhances Salt Stress Tolerance in Transgenic Nicotiana Benthamiana. Plant Cell Physiol. 2017, 58, 1673-1688. [CrossRef]

14. Lu, D.; Lin, W.; Gao, X.; Wu, S.; Cheng, C.; Avila, J.; Heese, A.; Devarenne, T.P.; He, P.; Shan, L. Direct Ubiquitination of Pattern Recognition Receptor FLS2 Attenuates Plant Innate Immunity. Science 2011, 332, 1439-1442. [CrossRef]

15. Zeng, L.R.; Qu, S.; Bordeos, A.; Yang, C.; Baraoidan, M.; Yan, H.; Xie, Q.; Nahm, B.H.; Leung, H.; Wang, G.L. Spotted leaf11, a Negative Regulator of Plant Cell Death and Defense, Encodes a U-Box/Armadillo Repeat Protein Endowed with E3 Ubiquitin Ligase Activity. Plant Cell 2004, 16, 2795-2808. [CrossRef]

16. Wiborg, J.; O'Shea, C.; Skriver, K. Biochemical Function of Typical and Variant Arabidopsis thaliana U-Box E3 Ubiquitin-Protein Ligases. Biochem. J. 2008, 413, 447-457. [CrossRef]

17. Zeng, L.R.; Park, C.H.; Venu, R.C.; Gough, J.; Wang, G.L. Classification, Expression Pattern, and E3 Ligase Activity Assay of Rice U-Box-Containing Proteins. Mol. Plant 2008, 1, 800-815. [CrossRef]

18. Kim, D.Y.; Lee, Y.J.; Hong, M.J.; Kim, J.H.; Seo, Y.W. Genome Wide Analysis of u-box e3 Ubiquitin Ligases in Wheat (Triticum aestivum L.). Int. J. Mol. Sci. 2021, 22, 2699. [CrossRef]

19. Cho, S.K.; Chung, H.S.; Ryu, M.Y.; Park, M.J.; Lee, M.M.; Bahk, Y.Y.; Kim, J.; Pai, H.S.; Kim, W.T. Heterologous Expression and Molecular and Cellular Characterization of CaPUB1 Encoding a Hot Pepper U-Box E3 Ubiquitin Ligase Homolog. Plant Physiol. 2006, 142, 1664-1682. [CrossRef]

20. González-Lamothe, R.; Tsitsigiannis, D.I.; Ludwig, A.A.; Panicot, M.; Shirasu, K.; Jones, J.D.G. The U-Box Protein CMPG1 Is Required for Efficient Activation of Defense Mechanisms Triggered by Multiple Resistance Genes in Tobacco and Tomato. Plant Cell 2006, 18, 1067-1083. [CrossRef]

21. Yang, C.W.; González-Lamothe, R.; Ewan, R.A.; Rowland, O.; Yoshioka, H.; Shenton, M.; Ye, H.; O’Donnell, E.; Jones, J.D.G.; Sadanandom, A. The E3 Ubiquitin Ligase Activity of Arabidopsis PLANT U-BOX17 and Its Functional Tobacco Homolog ACRE276 Are Required for Cell Death and Defense. Plant Cell 2006, 18, 1084-1098. [CrossRef]

22. Stone, S.L.; Anderson, E.M.; Mullen, R.T.; Goring, D.R. ARC1 Is an E3 Ubiquitin Ligase and Promotes the Ubiquitination of Proteins During the Rejection of Self-Incompatible Brassica Pollen. Plant Cell 2003, 15, 885-898. [CrossRef]

23. Liu, P.; Sherman-Broyles, S.; Nasrallah, M.E.E.; Nasrallah, J.B. A Cryptic Modifier Causing Transient Self-Incompatibility in Arabidopsis thaliana. Curr. Biol. 2007, 17, 734-740. [CrossRef]

24. Amador, V.; Monte, E.; García-Martínez, J.L.; Prat, S. Gibberellins Signal Nuclear Import of PHOR1, a Photoperiod-Responsive Protein with Homology to Drosophila armadillo. Cell 2001, 106, 343-354. [CrossRef]

25. Kim, M.; Cho, H.S.; Kim, D.M.; Lee, J.H.; Pai, H.S. CHRK1, a Chitinase-Related Receptor-Like Kinase, Interacts with NtPUB4, an Armadillo Repeat Protein, in Tobacco. Biochim. Biophys. Acta 2003, 1651, 50-59. [CrossRef]

26. Zhang, G.; Zhang, M.; Zhao, Z.; Ren, Y.; Li, Q.; Wang, W. Wheat TaPUB1 Modulates Plant Drought Stress Resistance by Improving Antioxidant Capability. Sci. Rep. 2017, 7,1-13. [CrossRef]

27. Byun, M.Y.; Cui, L.H.; Oh, T.K.; Jung, Y.J.; Lee, A.; Park, K.Y.; Kang, B.G.; Kim, W.T. Homologous U-Box E3 Ubiquitin Ligases OsPUB2 and OsPUB3 Are Involved in the Positive Regulation of Low Temperature Stress Response in Rice (Oryza sativa L.). Front. Plant Sci. 2017, 8, 16. [CrossRef] 
28. Hashizume, R.; Fukuda, M.; Maeda, I.; Nishikawa, H.; Oyake, D.; Yabuki, Y.; Ogata, H.; Ohta, T. The RING Heterodimer BRCA1-BARD1 Is a Ubiquitin Ligase Inactivated by a Breast Cancer-Derived Mutation. J. Biol. Chem. 2001, 276, 14537-14540. [CrossRef] [PubMed]

29. Chun, H.J.; Lim, L.H.; Cheong, M.S.; Baek, D.; Park, M.S.; Cho, H.M.; Lee, S.H.; Jin, B.J.; Cha, Y.J.; Lee, Y.B.; et al. Arabidopsis ccoaomt1 Plays a Role in Drought Stress Response via Ros- and Aba-Dependent Manners. Plants 2021, 10, 831. [CrossRef]

30. Chung, E.; Cho, C.W.; So, H.A.; Kang, J.S.; Chung, Y.S.; Lee, J.H. Overexpression of VrUBC1, a Mung Bean E2 UbiquitinConjugating Enzyme, Enhances Osmotic Stress Tolerance in Arabidopsis. PLoS ONE 2013, 8, e66056. [CrossRef]

31. Sato, H.; Takasaki, H.; Takahashi, F.; Suzuki, T.; Iuchi, S.; Mitsuda, N.; Ohme-Takagi, M.; Ikeda, M.; Seo, M.; Yamaguchi-Shinozaki, K.; et al. Arabidopsis thaliana NGATHA1 Transcription Factor Induces ABA Biosynthesis by Activating NCED3 Gene During Dehydration Stress. Proc. Natl. Acad. Sci. USA 2018, 115, E11178-E11187. [CrossRef] [PubMed]

32. Hrmova, M.; Hussain, S.S. Plant transcription factors involved in drought and associated stresses. Int. J. Mol. Sci. 2021, $22,5662$. [CrossRef] [PubMed]

33. Hu, H.; Dong, C.; Sun, D.; Hu, Y.; Xie, J. Genome-wide identification and analysis of U-box E3 ubiquitin-protein ligase gene family in banana. Int. J. Mol. Sci. 2018, 19, 3874. [CrossRef] [PubMed]

34. Fujii, H.; Zhu, J.K. Arabidopsis mutant deficient in 3 abscisic acid-activated protein kinases reveals critical roles in growth, reproduction, and stress. Proc. Natl. Acad. Sci. USA 2009, 106, 8380-8385. [CrossRef]

35. Adler, G.; Konrad, Z.; Zamir, L.; Mishra, A.K.; Raveh, D.; Bar-Zvi, D. The Arabidopsis paralogs, PUB46 and PUB48, encoding U-box E3 ubiquitin ligases, are essential for plant response to drought stress. BMC Plant Biol. 2017, 17, 1-12. [CrossRef]

36. Cruz De Carvalho, M.H. Drought stress and reactive oxygen species: Production, scavenging and signaling. Plant Signal. Behav. 2008, 3, 156-165. [CrossRef]

37. Noctor, G.; Foyer, C.H. Ascorbate and Glutathione: Keeping Active Oxygen under Control. Annu. Rev. Plant Biol. 1998, 49, 249-279. [CrossRef]

38. Chen, C.; Cui, X.; Zhang, P.; Wang, Z.; Zhang, J. Expression of the pyrroline-5-carboxylate reductase (P5CR) gene from the wild grapevine Vitis yeshanensis promotes drought resistance in transgenic Arabidopsis. Plant Physiol. Biochem. 2021, 168, 188-201. [CrossRef]

39. Tu, M.; Wang, X.; Zhu, Y.; Wang, D.; Zhang, X.; Cui, Y.; Li, Y.; Gao, M.; Li, Z.; Wang, Y.; et al. VlbZIP30 of Grapevine Functions in Dehydration Tolerance via the Abscisic Acid Core Signaling Pathway. Hortic. Res. 2018, 5, 49. [CrossRef]

40. Xu, J.; Chua, N.H. Dehydration Stress Activates Arabidopsis MPK6 to Signal DCP1 Phosphorylation. EMBO J. 2012, 31, 1975-1984. [CrossRef]

41. Sharma, M.; Pandey, A.; Pandey, G.K. Role of Plant U-BOX (PUB) Protein in Stress and Role of Plant U-BOX (PUB) Protein in Stress and Development. Plant Stress 2013, 7, 1-9.

42. Navarro, L.; Zipfel, C.; Rowland, O.; Keller, I.; Robatzek, S.; Boller, T.; Jones, J.D.G. The Transcriptional Innate Immune Response to flg22. Interplay and Overlap with Avr Gene-Dependent Defense Responses and Bacterial Pathogenesis. Plant Physiol. 2004, 135, 1113-1128. [CrossRef]

43. Li, Q.; Li, B.; Wang, J.; Chang, X.; Mao, X.; Jing, R. TaPUB15, a U-Box E3 Ubiquitin Ligase Gene from Wheat, Enhances Salt Tolerance in Rice. Food Energy Secur. 2021, 10, e250. [CrossRef]

44. Cutler, S.R.; Rodriguez, P.L.; Finkelstein, R.R.; Abrams, S.R. Abscisic Acid: Emergence of a Core Signaling Network. Annu. Rev. Plant Biol. 2010, 61, 651-679. [CrossRef]

45. Zheng, D.; Song, F. Expression Patterns and Functional Analysis of E3 Ubiquitin Ligase Genes in Rice. ResearchSquare 2021. [CrossRef]

46. Hatakeyama, S.; Nakayama, K.I.I. U-Box Proteins as a New Family of Ubiquitin Ligases. Biochem. Biophys. Res. Commun. 2003, 302, 635-645. [CrossRef]

47. Trujillo, M. News from the PUB: Plant U-Box type E3 Ubiquitin Ligases. J. Exp. Bot. 2018, 69, 371-384. [CrossRef]

48. Koegl, M.; Hoppe, T.; Schlenker, S.; Ulrich, H.D.; Mayer, T.U.; Jentsch, S. A Novel Ubiquitination Factor, E4, Is Involved in Multiubiquitin Chain Assembly. Cell 1999, 96, 635-644. [CrossRef]

49. Cao, Y.; Dai, Y.; Cui, S.; Ma, L. Histone H2B Monoubiquitination in the Chromatin of Flowering Locus C Regulates Flowering Time in Arabidopsis. Plant Cell 2008, 20, 2586-2602. [CrossRef]

50. Nelson, B.K.; Cai, X.; Nebenführ, A. A Multicolored Set of In Vivo Organelle Markers for Co-Localization Studies in Arabidopsis and Other Plants. Plant J. 2007, 51, 1126-1136. [CrossRef]

51. Kim, J.H.; Kim, M.S.; Prasad, D.; Jung, W.J.; Seo, Y.W. Molecular Characterization of the Wheat Putative Proline-Rich Protein TaELF7 and Its Involvement in the Negative Regulation of Arabidopsis Flowering. J. Plant Physiol. 2021, 262, 153439. [CrossRef]

52. Kumar, S.; Stecher, G.; Li, M.; Knyaz, C.; Tamura, K.; Mega, X. MEGA X: Molecular Evolutionary Genetics Analysis Across Computing Platforms. Mol. Biol. Evol. 2018, 35, 1547-1549. [CrossRef]

53. Livak, K.J.; Schmittgen, T.D. Analysis of Relative Gene Expression Data Using Real-Time Quantitative PCR and the 2- $\Delta \Delta C \mathrm{C}$ Method. Methods 2001, 25, 402-408. [CrossRef]

54. Kim, J.H.; Khan, I.U.; Kim, M.S.; Seo, Y.W. Functional characterization of wheat histone H2B monoubiquitination enzyme TaHUB2 in response to vernalization in Keumkang (Triticum aestivum L.). J. Plant Interact. 2021, 16, 93-103. [CrossRef] 
55. Lim, S.D.; Cho, H.Y.; Park, Y.C.; Ham, D.J.; Lee, J.K.; Jang, C.S. The Rice Ring Finger E3 Ligase, OsHCI1, Drives Nuclear Export of Multiple Substrate Proteins and Its Heterogeneous Overexpression Enhances Acquired Thermotolerance. J. Exp. Bot. 2013, 64, 2899-2914. [CrossRef]

56. Clough, S.J.; Bent, A.F. Floral Dip: A Simplified Method for Agrobacterium-Mediated Transformation of Arabidopsis thaliana. Plant J. 1998, 16, 735-743. [CrossRef] 